American Journal of Pharmaceutical Education 2019; 83 (2) Article 7301.

\title{
COMMENTARY
}

\section{The Conscience of a Pharmacist}

\author{
Brian L. Erstad, PharmD \\ University of Arizona College of Pharmacy, Tucson, Arizona \\ Submitted July 31, 2018; accepted October 9, 2018; published March 2019.
}

\begin{abstract}
The purpose of this commentary is to attempt to provide some insight into conscience-clause cases from the perspective of a pharmacist and an academician. Health professionals, including pharmacists, have a social contract with the patients we serve in which the patients give us a level of status not given to non-professionals, and, in return, we agree to put the interests of our patients above our own. Therefore, any discussion of a right-to-refuse service needs to begin with a discussion of the duties and responsibilities of the health professional to the patient.
\end{abstract}

Keywords: moral duties; pharmacist; clinical ethics; pharmacy students; health professions

Two recent cases of Arizona pharmacists refusing to fill prescriptions based on conscience-clause legislation has received much media attention and has led to questions about ethical obligations deserving of discussion in the education of pharmacy students and their eventual roles as practicing pharmacists. On the assumption that the general details of the media reports are correct, a Walgreens pharmacist refused to fill a prescription for a medication prescribed to expulse fetal remains, and, in a separate incident, a CVS pharmacist refused to fill a prescription for hormone therapy for a transgender woman. The reader is referred to the various media reports for more details, but, suffice it to say, there were troubling statements about how each of these incidents were handled by the involved pharmacist, and there were a number of comments on social media that were very critical of pharmacists in general. ${ }^{1-4}$ The purpose of this commentary is to attempt to provide some insight into the nuances of conscience-clause cases from the perspective of a pharmacist and an academician. I doubt my thoughts will change the opinions of readers who strongly oppose or strongly support conscience-clause legislation, but that is not my intent.

As a pharmacist with more than 40 years of practice experience, mostly in hospital settings as part of an interprofessional patient-care team, I often encounter situations when I question a patient's prescription on the basis of efficacy, safety, or other patient-specific concerns. Resolution of such concerns requires a careful review of the patient's health information including the current

Corresponding Author: Brian L. Erstad, Department of Pharmacy Practice \& Science, University of Arizona College of Pharmacy, 1295 N. Martin Ave., Tucson, Arizona 85721. Tel: 520-626-4289. Fax: 520-626-7355. E-mail:

erstad@pharmacy.arizona.edu problem list, medical history, laboratory and other testing results, and discussions with the physician and patient. In some cases, my concerns are alleviated after this record review and discussion; while, in others, the prescriber agrees to change the prescription based on my recommendation. Fortunately, I have rarely encountered situations in which I felt compelled to refuse to fill a prescription based on what I perceived to be a clear risk exceeding the potential benefit for a patient. Of note, the actual dispensing of the medication is one of the final steps in this patient care process articulated by national pharmacy organizations working under the auspices of the Joint Commission of Pharmacy Practitioners (JCPP). ${ }^{5}$

The process begins with data collection, followed by an assessment, development of a plan, implementation of the plan (dispensing), and monitoring and evaluating the effectiveness of the plan with any as needed modification to achieve the goals of the therapy. The actual dispensing of medication occurs, generally, only after the higher level of assessment and evaluation described above, and it is increasingly being performed by supportive personnel or automated dispensing machines.

This has raised questions about the role of many community pharmacists who traditionally have not had access to important data needed for the first step of the patient care process that defines a valid patientpractitioner relationship. This is currently a source of much discussion and debate within the pharmacy profession, but I am confident this issue will eventually be resolved as pharmacists continue to be integrated into interprofessional health care teams with access to the necessary information to fulfill their role as experts concerned with medication optimization.

The cases of the Arizona chain store pharmacists refusing to dispense what appear to be legally valid 


\section{American Journal of Pharmaceutical Education 2019; 83 (2) Article 7301.}

prescriptions based on moral or religious grounds (in other words, the conscience clauses) has implications for what it means to be a health professional. Health professionals, including pharmacists, have a social contract with the patients we serve in which the patients give us a level of status not given to non-professionals, and, in return, we agree to put the interests of our patients above our own.

Indeed, this social contract of altruism is embedded in the first line of the Oath of a Pharmacist that is taken by many pharmacy students during convocation or graduation ceremonies, "I promise to devote myself to a lifetime of service to others through the profession of pharmacy." Therefore, any discussion of a right-to-refuse service needs to begin with a discussion of the duties and responsibilities of the health professional to the patient in what has been described as a covenantal relationship. The obligations of the health care professional in this relationship become more complex as more direct patient care is provided, particularly by pharmacists in community pharmacies. ${ }^{6,7}$

Medical professionals have traditionally abided by a set of ethical tenets including autonomy, justice, beneficence and non-maleficence. Much emphasis is often placed in medicine on non-maleficence, or "do no harm," but the other ethical tenets deserve further consideration when discussing the right-to-refuse legislation. Pharmacists have an obligation to do what is in the best interest of their patients (beneficence), to treat patients justly or fairly (justice), and to respect a patient's decision to know and do what is best for them (autonomy). To put a pharmacist's autonomy above the ethical commitments owed to the patient is fraught with challenges, regardless of legal protections for pharmacists provided through legislation such as the conscience clauses. A refusal to dispense a legally valid prescription is even more questionable when the pharmacist does not have access to complete information, the first step of the patient care process, needed to make a fully informed decision concerning the well-being of another person.

I have been a faculty member in a college of pharmacy for the latter part of my career. As with other pharmacy colleges and schools, our curriculum involves educating our students about pharmacy law and, albeit to a lesser extent, general ethical considerations. The two recent cases in Arizona of Walgreen's and CVS pharmacists' refusal to dispense miscarriage and hormone therapies, respectively, have both legal and ethical lessons for our students. Several states have passed some version of conscience clauses. In Arizona, Arizona Revised Statute (A.R.S.) § 36-2154 refers to a "pharmacy, hospital or health professional, or any employee of a phar- macy, hospital or health professional" when it goes on to state "is not required to facilitate or participate in the provision of an abortion, abortion medication, emergency contraception or any medication or device intended to inhibit or prevent implantation of a fertilized ovum." Furthermore, the statute requires that the objection be stated in writing and that the prescription order be returned to the patient.

I will let the Board of Pharmacy, my readers, the pharmacists' respective employers and possibly the civil justice system decide if the pharmacists in the Arizona cases conformed to this statute, or if indeed such statutes are appropriate at all given the challenges associated with their interpretation by pharmacists and their functionality by pharmacies. Of note, a number of medical ethicists are co-signatories to a complaint that was sent to the Arizona State Board of Pharmacy about the pharmacist who refused to dispense the medication used to expulse retained fetal remains. ${ }^{9}$ The complaint by a group of medical bioethicists stated that they believed the pharmacist demonstrated unprofessional conduct (a statutory reason for possible disciplinary action by the Arizona Board of Pharmacy: A.R.S. § 32-1927) that injured the patient in several ways through lack of knowledge and inaccurate inferences about the purpose of the medication, and by inappropriately inserting himself in the physician-patient relationship.

Student-faculty discussions of the ethical obligations of pharmacists should not be avoided in an attempt to evade controversial issues. Rather, controversial and widely discussed topics in the lay media such as pharmacists' refusal-to-dispense should be used to capture pharmacy students' attention and serve as learning opportunities related to professionalism, law, ethics and morals. ${ }^{10}$

Accreditation standards for pharmacy education currently include outcomes related to ethics and ethical dilemmas in patient care, so minimal expectations have been articulated. ${ }^{11}$ However, the standards could not and should not try to detail every type of ethical dilemma that might arise in the practice setting. For our pharmacy students, it is important that they learn that several health profession organizations (including those related to pharmacy) have released statements on conscience clauses that include ethical obligations beyond any legal considerations for a health professional who exercises a conscience clause prerogative. These obligations include professional responsibilities related to handling the situation in a nonjudgmental, timely and confidential manner - this is not a time for grandstanding or overt obstructionism.

Recent cases involving conscience clauses will lead to further discussions about how our pharmacy colleges and schools are educating our students on these issues. 


\section{American Journal of Pharmaceutical Education 2019; 83 (2) Article 7301.}

This is appropriate not only because of state statutes pertaining to this issue, but also because of proposed rulemaking at the federal level and continued expansion of pharmacist privileging. For example, Proposed Rule 45 CFR Part 88 further protecting statutory conscience rights was published in January 2018 in the Federal Register. ${ }^{12}$ The rule would give U.S. Department of Health and Human Services (HHS) Office for Civil Rights (OCR) authority for compliance reviews, investigations and use of enforcement tools for health service programs or research activities in programs administered by HHS.

The rule defines a health care entity as not only including health care professionals, but also participants involved in health profession training as well as applicants and participants training or studying in the health professions. Also, in January 2018, HHS announced the formation of a new Conscience and Religious Freedom Division to be housed in the OCR. As stated in the announcement, which referred to a promise about conscience and religious freedom that President Trump made to the American people, "The creation of the new division will provide HHS with the focus it needs to more vigorously and effectively enforce existing laws protecting the rights of conscience and religious freedom, the first freedom protected in the Bill of Rights."13

Expansion of pharmacist privileging has occurred in conjunction with the recognition of the pharmacist as experts in medication optimization. Health professional workforce shortages and newer models of health care delivery such as interprofessional, team-based community care create opportunities and challenges for the pharmacy profession. Pharmacists have been recognized as health care professionals who can help to mitigate the primary care provider shortage, which has been a long-standing problem particularly in rural, medically underserved areas. ${ }^{14}$ In conjunction with these new roles, pharmacists have increased responsibilities that will necessitate increased awareness of the ethical dilemmas that are likely to occur with privileges related to prescribing.

Besides health professionals and health profession students, it is also time that patients and the public become more educated on conscience clause issues, since legislative and enforcement activities are only likely to increase in these highly polarized and politicized times.

\section{ACKNOWLEDGMENTS}

The author is grateful to C. Edwin Webb, PharmD, MPH and Elizabeth Hall-Lipsy, JD, MPH, for their thoughtful review of this paper and suggestions for improvements. The information and conclusions are those of the author.

\section{REFERENCES}

1. Cullinane S. CNN. Walgreens pharmacist refuses to fill woman's prescription to induce a miscarriage. https:/www.cnn.com/2018/06/ 25/health/arizona-prescription-walgreens-miscarriage/index.html. Published June 25, 2018. Accessed October 2, 2018.

2. Chow K. NPR. Walgreens pharmacist refuses to provide drug for Ariz. woman with unviable pregnancy. https://www.npr.org/2018/06/ 25/623307762/walgreens-pharmacist-denies-drug-for-woman-withunviable-pregnancy. Published June 25, 2018. Accessed October 2, 2018 .

3. Jacobs J. The New York Times. Transgender woman says CVS pharmacist refused to fill hormone prescription. https://www. nytimes.com/2018/07/20/us/cvs-pharmacy-transgender-woman-nyt. html. Published July 20, 2018. Accessed October 2, 2018.

4. Grinberg E, Campisi J. CNN. CVS apologizes after a pharmacist refused to fill a transgender woman's prescription. https://www.cnn. com/2018/07/20/health/arizona-trans-woman-cvs-pharmacist-

prescription-trnd/index.html. Published July 20, 2018. Updated July 22, 2018. Accessed October 2, 2018.

5. Joint Commission of Pharmacy Practitioners. The Pharmacists' Patient Care Process. https://jcpp.net/patient-care-process/. Published May 29, 2014. Accessed October 2, 2018.

6. Crawshaw R, Rogers DE, Pellegrino ED, et al. Patient-physician covenant. JAMA. 1995;273:1553.

7. Haddad AM. Reflections on the pharmacist-patient covenant. Am J Pharm Educ. 2018;82:Article 6806.

8. Arizona State Legislature. Arizona Revised Statutes. Title $36-$ Public Health and Safety. Chapter 20 ABORTION. https://www. azleg.gov/arsDetail/?title=36. Accessed March 8, 2019.

9. Miles SH, Caplan A. Confusion and Conscientious Objection in Arizona. Bioethics.net. http://www.bioethics.net/2018/07/confusionand-conscientious-objection-in-arizona/. Published July 1, 2018. Accessed October 2, 2018.

10. DiPiro JT. The pharmacist's right to refuse: a learning opportunity. Am J Pharm Educ. 2005;69:Article 92.

11. Accreditation Council for Pharmacy Education. PharmD program accreditation. https://www.acpe-accredit.org/pharmdprogram-accreditation/. Accessed October 2, 2018.

12. Federal Register. Protecting Statutory Conscience Rights in Health Care; Delegations of Authority. A Proposed Rule by the Health and Human Services Department on 01/26/2018. https://www. federalregister.gov/documents/2018/01/26/2018-01226/protectingstatutory-conscience-rights-in-health-care-delegations-of-authority. Accessed March 8, 2019.

13. U.S. Department of Health \& Human Services. HHS Announces New Conscience and Religious Freedom Division. https://www.hhs. gov/about/news/2018/01/18/hhs-ocr-announces-new-conscienceand-religious-freedom-division.html. Published January 18, 2018. Accessed March 8, 2019.

14. Smith M, Bates DW, Bodenheimer TS. Pharmacists belong in accountable care organizations and integrated care teams. Health Aff. 2013;32:1963-1970. 